\title{
Hydrolytic Degradation of Polyethylene Terephthalate by Cutinase Enzyme Derived from Fungal Biomass- Molecular Characterization
}

\author{
Saravanan Anbalagan 1,*位, Hemavathy Raghava Reddiar Venkatakrishnan 1(D), \\ Jayasree Ravindran ${ }^{1}$, Jeyasri Sathyamoorthy ${ }^{1} \mathbb{D}$, Kiruthika Arakonam Rangabashyam ${ }^{1} \mathbb{D}$, Yaashikaa \\ Ponnambalam Ragini ${ }^{2}$ (D), Jeevanantham Sathasivam 1 ${ }^{\text {(D) }}$, Karishma Sureshbabu ${ }^{1}$ (D) \\ 1 Department of Biotechnology, Rajalakshmi Engineering College, Chennai 602105, Tamilnadu, India; \\ saravanan.a@rajalakshmi.edu.in (A.S.); hemavathy.rv@rajalakshmi.edu.in (R.V.H.); jayasree.r@ rajalakshmi.edu.in \\ (R.J.); jeyasri.s.2017.bt@rajalakshmi.edu.in（S.J.); kiruthika.ar.2017.bt@rajalakshmi.edu.in $\quad$ (A.R.K.); \\ jeevananthamsbt31@gmail.com (S.J.); karishsuresh@gmail.com (S.K.); \\ 2 Department of Biotechnology, Saveetha School of Engineering, Chennai 602105, Tamilnadu, India; \\ yaashikaapr.sse@ saveetha.com (P.R.Y.); \\ * Correspondence: saravanan.a@rajalakshmi.edu.in;
}

Scopus Author ID 56950442900

Received: 15.02.2021; Revised: 25.03.2021; Accepted: 1.04.2021; Published: 20.04.2021

\begin{abstract}
Polyethylene Terephthalate (PET) is utilized worldwide in plastic items, and its aggregation in the earth has turned into a worldwide concern. The hydrolysis of PET was done by cutinase and lipase enzyme. Lipase and cutinase enzymes were extracted from the fungal species isolated from soil. The isolated fungal species were identified as Aspergillus tamarii and Penicillium crustosum by $18 \mathrm{~S}$ rRNA sequencing. Biodegradation test, cutinase enzyme-catalyzed PET hydrolysis, and different assays were conducted to elucidate PET hydrolysis by the extracted enzymes. These components incorporate cell surface connection inside biofilms, enzyme catalysts engaged with oxidation or hydrolysis of the plastic polymer, metabolic pathways in charge of take-up and osmosis of plastic parts, and synthetic factors favorable or inhibitory to the biodegradation procedure. The degradation of plastic was identified with terephthalic acid release (TPA) release as they are made of two monomeric units. Characterization studies such as FTIR and SEM analysis have exhibited loss of weight or change in physical properties, such as elasticity and the examination of Spectroscopic.
\end{abstract}

Keywords: polyethylene terephthalate (PET); cutinase; lipase; Aspergillus tamarii; Penicillium crustosum.

(C) 2021 by the authors. This article is an open-access article distributed under the terms and conditions of the Creative Commons Attribution (CC BY) license (https://creativecommons.org/licenses/by/4.0/).

\section{Introduction}

The most common synthetic polymer, Polyethylene terephthalate (PET), is used to manufacture plastic products that are non-biodegradable [1]. Due to their favorable physical properties such as durability, plasticity, lightweight, and transparency, they are widely integrated into the consumer world [2,3]. PET consists of aromatic compounds which are chemically inert, providing resistance to any kind of microbial degradation [4]. The important PET applications are the manufacture of soft drink bottles, water bottles, beer bottles, ovenable pre-prepared food trays [5].On average, 275 million tons of plastic is being generated. These generated wastes are disposed of either by landfills or by dumping into the water bodies instead of recycling [6]. In the disposal method, they undergo photodegradation followed by 
bacterial decomposition. They show a very low rate of hydrolysis; thus, they take about 100 years to degrade plastics. In addition, they produce toxic substances, which affect soil fertility during decomposition, whereas in the oceans, they affect the aquatic organisms, which results in their mortality $[7,8]$. There are two types of plastics: Biodegradable and Non-bio-degradable plastics. PET and PVC (polyvinyl chloride) are the most common polymers used in the consumer world, which are non-biodegradable [9]. These are highly toxic to human health, which leads to lifelong health threats such as cancer and other immune disorders. They release mercury, dioxins, and phthalates on decomposition [10,11]. The biodegradable plastics are not quickly degraded. Even with the favorable conditions, their half-life period is 389 days which is roughly one year. This indicates that their complete degradation takes about $2 \frac{1}{2}$ years [12]. Within this period, there is a high possibility that they would end up in the oceans due to heavy storms. Also, sea debris increases if they sink beneath. Therefore, it is very important to reduce PET accumulation without affecting the ecosystem [13].

So far, the techniques studied by the researchers to degrade plastics are bacterial degradation [14, 15], fungal degradation [16], landfill techniques [17], composting method [18], mechanistic implications [19], photodegradation [20]. All these techniques are aimed to reduce the degrading duration [20]. The enzyme class Esterases can break the ester bond in a polymer. Hydrolytic enzymes [21] do this depolymerization. So far, enzymes reported to degrade PET are cutinases, lipases, serine esterases, and p-nitrophenylesterases, among the other esterases [22, 23]. Cutinase, an extracellular enzyme, has the ability to release TPA when PET acts as a substrate. Cutinase is responsible for the virulence activity in the phytopathogenic bacteria and fungi. Cutinase helps them break the cutin (a polyester lining the leaves to prevent evaporation) to gain entry into the cell for infection [24-26]. Cutinase has Ser His Asp Glu residues similar to that of lipase, forming a catalytic triad. In addition, cutinase resembles the activity of lipase [27]. Lipase and catalyzes hydrolyze and synthesize triacylglycerols. Lipases are easily found in all organisms, which can be used in esterification, acidolysis, alcoholysis, aminolysis etc. This microorganism has proved to produce lipase both by solid-state and submerged fermentation [28]. Lipase-mediated reactions are mostly reversible [29, 30]. In fungi, lipases are found as an extracellular product, and hence they have well-known applications such as detergent formulations, dairy industry, agrochemical industry, paper manufacture, nutrition, cosmetics, leather manufacture, and pharmaceutical processing [31]. Lipase peels the superficial PET layers.

To hydrolyze PET, both cutinase and lipase act synergistically, thereby releasing TPA (terephthalic acid) and ethylene glycol. Cutinase can hydrolyze PET until MHET (an intermediate) is formed because MHET acts as a competitive inhibitor and stops the conversion. But, lipase has no limitation, i.e., it completely converts the polyester to TPA [32, 33]. Hence, the lipase overcomes the disadvantage of cutinase. Thus, both these enzymes help in the complete conversion of PET to TPA and ethylene glycol [34]. They are one of the enzymes which bind to PET, i.e., as a substrate. TPA and Ethylene glycol are monomeric units. The major applications of products (or) monomeric units are photographic film manufacture; TPA acts as a carrier in paint also used as an adhesive [35], whereas Ethylene glycol is used as electrolytic capacitors and in the manufacture of detergents [36].

The scope of this investigation has endeavored to recommend the plausible debasement component by a microbial enzyme such as lipase and cutinase, a noteworthy catalyst in charge of the debasement of plastic and comparative polymeric substances. In this work, extracellular lipase was extracted from Aspergillus japonicus. Similarly, cutinase was extracted from 
Saccharomyces sp. The concentration of enzymes in microorganisms and degradation products of microbial consortia was tried by several methods. Distinctive characterization studies have been discussed, which for the most part, are utilized for assessing the advancement of the debasement process and help us to get the transitional advances unmistakably alongside debasement. The outcomes from these investigations recommended that PET might have great communication towards the microbial lipase and cutinase with stable authoritative and cooperating powers, which could be one reason for the degradative components.

\section{Materials and Methods}

\subsection{Preparation of PET films.}

An empty non-carbonated water bottle was taken. It is washed using sterile double distilled water to remove any impurities. The bottle is then cut into dimensions of about $2 \times 2$ $\mathrm{cm}^{2}$. The films were again washed and dried to store in a clean desiccator.

\subsection{Isolation and screening of lipase-producing fungal species.}

Soil samples were collected from college premises (Rajalakshmi Engineering College, Chennai, Tamil Nadu, India) and serial diluted $\left(10^{-1}\right.$ to $\left.10^{-6}\right)$ using sterile double distilled water. Each dilution was streaked onto YPSS agar (Yeast phosphate soluble starch) containing Rhodamine B (fluorescent dye) and olive oil as substrate. The YPSS agar plates were incubated at $27{ }^{\circ} \mathrm{C}$ for 28 days. During the growth, fluorescent halo formation around a colony indicates the production of lipase. The fungal species were identified by $18 \mathrm{~S}$ rRNA sequencing. From the agar plate single colony was transferred to the growth medium for mass production of lipase enzyme.

\subsubsection{Screening of cutinase producing fungal species.}

The diluted soil sample was inoculated to a sterile YPSS medium. Screening of cutinase-producing fungal species was carried out using the Rhodamine Agar plate method. Rhodamine B colorant dye along with cutin substrate was added with YPSS agar medium and mixed well. The medium was poured into a Petri plate, and a well of about $3 \mathrm{~mm}$ was made. $10 \mu \mathrm{L}$ of culture supernatant was poured into the well and incubated at $27{ }^{\circ} \mathrm{C}$ for 3 days. The halo-fluorescent zone's appearance was found around the well under UV light after $48-72 \mathrm{~h}$ of incubation at $27^{\circ} \mathrm{C}$, which indicates the cutinase production by the isolated fungal species.

\subsubsection{Identification of fungal species.}

After the confirmation of lipase and cutinase enzyme production, the screened fungal species were identified using the $18 \mathrm{~S}$ rRNA sequencing method. The DNA of the screened fungal strains was extracted using the standard procedure, and the extracted DNA concentration was measured by Qubit 3.0. Extracted DNA was amplified by Polymerase Chain Reaction (PCR) using the forward primer (ITS1 - 5' TCCGTAGGTGAACCTGCGG 3') and reverse primer (ITS4 - 5' TCCTCCGCTTATTGATATGC 3'). For the polymerase chain reaction, 5 $\mu 1$ of extracted DNA was mixed with $25 \mu 1$ of PCR reaction solution, which contains forward and reverses primers, deionized water, and Taq Master Mix. PCR reaction was carried out for 25 cycles as three stages including (i) Denaturation $\left(95^{\circ} \mathrm{C}\right.$ ), (ii) Annealing $\left(55^{\circ} \mathrm{C}\right.$ ), and (iii) Extension $\left(72^{\circ} \mathrm{C}\right)$. After DNA amplification by PCR, the unincorporated PCR reaction 
mixtures were separated from the PCR reaction output. The purified PCR product was sequenced by using single-pass sequencing. The amplified DNA samples were subjected to electrophoresis in an ABI 3730xl sequencer at Yaazh Xenomics, Chennai, Tamil Nadu, India. Sequenced results of both the fungal species were compared with other sequences using NCBI blast similarity search tool. The multiple sequence alignment of sequences was performed using MUSCLE 3.7 to remove the poorly aligned sequences. Phylogenetic analysis was performed, and a phylogenetic tree was constructed using PhyML 3.0 aLRT program.

\subsection{Production of lipase.}

The selected strain was inoculated into the growth media (YPSS broth) containing 1.5 $\%$ olive oil as substrate. The isolated fungal species were inoculated into the YPSS broth containing $1.5 \%$ olive oil and incubated in an orbital shaker at $27{ }^{\circ} \mathrm{C}$ for 28 days. After incubation, the culture broth was centrifuged at $6000 \mathrm{rpm}$ for $40 \mathrm{~min}$ in a cooling centrifuge. The pellet was dried and suspended in Tris- $\mathrm{HCl}$ buffer for preservation.

\subsection{Lipase assay.}

The activity of the lipase enzyme was carried out by the lipase assay method. The presence of lipase was detected using the Lowry method and titrimetric analysis.

\subsubsection{Titrimetric analysis.}

In a set of $50 \mathrm{ml}$ of the volumetric flask, $2.5 \mathrm{ml}$ of deionized water, $1 \mathrm{ml}$ of buffer, $3 \mathrm{ml}$ of the substrate were added and blended using a vortex. The mixture was incubated for 30 mins at room temperature. After incubation, $1 \mathrm{~mL}$ of enzyme solution was added, the flaks were labeled as test, and another flask without enzyme was named as blank. Then, $3 \mathrm{~mL}$ of $75 \%$ ethanol and few drops of phenolphthalein indicator were added to both the flasks. The flasks (test and blank) were titrated against $\mathrm{NaOH}$ until the appearance of pink color. The burette reading was noted to calculate the activity using the formula,

\section{(volume of NaOH) (Molarity of NaOH) $1000 \times 2$ (Dilution factor) \\ $\mathrm{Units} / \mathrm{mL}$ (enzyme) = (volume of enzyme)}

\subsubsection{Estimation by Lowry's method.}

Lowry's method estimation was carried out by plotting a standard graph using standard BSA (Bovine serum albumin). The different BSA concentrations (0.05, 0.10, 0.15, 0.20, 0.25 $\mathrm{mg} / \mathrm{ml}$ ) were taken in a separate test tube followed by suspended in Tris- $\mathrm{HCl}$ buffer, making up to $1 \mathrm{ml}$ as blank. In each of 6 test tubes (blank and Test) $1 \mathrm{ml}$ reagent $\mathrm{A}$ ( $2 \mathrm{~g} \mathrm{Na}-\mathrm{K}$ tartarate, $\left.100 \mathrm{~g} \mathrm{Na}_{2} \mathrm{CO}_{3}, 500 \mathrm{ml}(1 \mathrm{~N}) \mathrm{NaOH}\right)$ was added, followed by incubation at $50{ }^{\circ} \mathrm{C}$ for $10 \mathrm{~min}$. After incubation, $0.1 \mathrm{ml}$ of reagent $\mathrm{B}\left(1 \mathrm{~g} \mathrm{CuSO}_{4} .5 \mathrm{H}_{2} \mathrm{O}, 90 \mathrm{ml}\right.$ water, $10 \mathrm{ml}(1 \mathrm{~N}) \mathrm{NaOH}, 2 \mathrm{~g}$ $\mathrm{Na}-\mathrm{K}$ tartarate) was added to the reaction mixture. The mixture was kept in the incubator and incubated at room temperature for $10 \mathrm{mins}$. After the incubation, $3 \mathrm{ml}$ of folin's reagent mixture was added. The sample was recorded in calorimetric at the absorbance at $650 \mathrm{~nm}$. The graph was plotted using the concentration of known standard against its absorbance. The unknown absorbance in the graph gives the concentration of enzyme present in units per $\mathrm{mL}$. 


\subsection{Preparation of cutin.}

Ripe apples with undamaged peel were purchased from the local market. The fruit was peeled, and the peel was added to boiling hexane (or) oxalate buffer solution with $\mathrm{pH} 3.5$ for $15-20$ min until devoid of pulp. Then, they were filtered, washed, and dried at $45^{\circ} \mathrm{C}$ in a hot air oven. The resulting dried and powdered cutin was stored in a sterile desiccator.

\subsection{Rhodamine agar plate assay.}

The ability to produce an enzyme (cutinase) by an isolated fungal strain was confirmed using Rhodamine Agar plate assay. The assay was performed in YPSS agar media consisting of $15 \mathrm{~g} / \mathrm{L}$ soluble starch, $4 \mathrm{~g} / \mathrm{L}$ yeast extract, $1 \mathrm{~g} / \mathrm{L} \mathrm{K} 2 \mathrm{HPO}_{4}, 0.5 \mathrm{~g} / \mathrm{L} \mathrm{MgSO} 4.7 \mathrm{H}_{2} \mathrm{O}, 15 \mathrm{~g} / \mathrm{L}$ Agar, $3 \%$ olive oil (v/v). The sterilized medium was poured into the Petri dishes, and plates were allowed for solidification. After solidification, $3 \mathrm{~mm}$ wells were created in the solidified YPSS agar plates, and $10 \mu \mathrm{L}$ of isolated fungal culture supernatant was added to the wells. The cutinase enzyme activity was identified as a fluorescent halo under UV illumination light after $24 \mathrm{~h}$ incubation at $27^{\circ} \mathrm{C}$.

\subsection{Production of cutinase.}

The isolated fungal strain was inoculated into the YPSS growth media containing $1 \%$ cutin as substrate and incubated in a shaker for 14 days at $27{ }^{\circ} \mathrm{C}$. After 14 days of incubation, the supernatant was collected from culture using a centrifuge. To the supernatant, cold acetone precipitation was performed at $4{ }^{\circ} \mathrm{C}$. Then, the precipitating mixture was centrifuged for 10 min to collect the pellet. The pellet was dried and suspended in Tris- $\mathrm{HCl}$ buffer for storage.

\subsection{Total protein content in YPSS broth.}

2.8.1. Estimation by Lowry's method.

Lowry's estimation was carried out by plotting a standard graph using standard BSA (Bovine serum albumin). The different BSA concentrations (0.02, 0.04, 0.06, 0.08, and 0.10 $\mathrm{mg} / \mathrm{mL}$ ) were taken in separate test tubes followed by suspended in Tris- $\mathrm{HCl}$ buffer, making up to $1 \mathrm{~mL}$ as blank. In each of 6 test tubes (blank and Test) $1 \mathrm{~mL}$ reagent $\mathrm{A}$ ( $2 \mathrm{~g} \mathrm{Na}-\mathrm{K}$ tartarate, $100 \mathrm{~g} \mathrm{Na}_{2} \mathrm{CO}_{3}, 500 \mathrm{~mL} 1 \mathrm{~N} \mathrm{NaOH}$ was added followed by incubated at $50^{\circ} \mathrm{C}$ for $10 \mathrm{~min}$. After incubation, $0.1 \mathrm{~mL}$ of reagent $\mathrm{B}\left(1 \mathrm{~g} \mathrm{CuSO}_{4} .5 \mathrm{H}_{2} \mathrm{O}, 90 \mathrm{~mL}\right.$ water, $10 \mathrm{~mL}(1 \mathrm{~N}) \mathrm{NaOH}, 2 \mathrm{~g}$ of $\mathrm{Na}-\mathrm{K}$ tartarate was added to the reaction mixture. The mixture was kept in an incubator at room temperature for $10 \mathrm{~min}$. After the incubation, $3 \mathrm{~mL}$ of folin reagent mixture was added. The sample was recorded in calorimetric at the absorbance at $650 \mathrm{~nm}$. The graph was plotted using the concentration of known standard against its absorbance. The unknown absorbance in the graph gives the concentration of enzyme present in units per $\mathrm{mL}$.

\subsection{Biodegradation test.}

2.9.1. Efficiency of hydrolysis in soil.

The non-carbonated water bottles were collected, and PET films were prepared. The sterile PET films were buried in the soil, and the pieces were collected and preserved in a dry desiccator. 


\subsubsection{Biodegradation in liquid media.}

The prepared $2 \times 2 \mathrm{~cm}^{2}$ of PET films were added to the $250 \mathrm{~mL}$ conical flask containing $100 \mathrm{~mL}$ of sterilized YPSS broth. $2 \mathrm{~mL}$ of both the extracted enzymes cutinase and lipase were added into the $250 \mathrm{~mL}$ conical flask. Two samples (PET films) were collected after 30 days of incubation for SEM and FTIR analysis.

\subsubsection{Test for the release of TPA and PEG.}

The supernatant of PET films incubated in liquid media was collected, and the sample was tested for HPLC. The mobile phase was prepared using $70 \%$ distilled water, $20 \%$ acetonitrile, and $10 \%$ formic acid solution (v/v) at a $1 \mathrm{~mL} / \mathrm{min}$ flow rate. The standard calibration curves of TPA and PEG were constructed by plotting the peak area of TPA and PEG at a wavelength of $244 \mathrm{~nm}$ versus concentrations of standard solutions. The HPLC system consisted of a Waters 2795 separation module and a Waters 2996 photodiode array detector (Milford, MA). The separation was carried out on a Phenomenex Synergi Hydro-RP column (4 mm, $250 \mathrm{~mm}, 4.6 \mathrm{~mm}$ ) run under isocratic conditions.

\subsection{Cutinase catalyzed polyethylene terephthalate (PET) hydrolysis.}

Cutinase catalyzed Polyethylene Terephthalate (PET) hydrolysis was examined by $\mathrm{pH}-$ stat apparatus. PET hydrolysis by the cutinase enzyme reactions was performed using the reaction mixture containing $10 \%$ glycerol and $0.5 \mathrm{mM}$ Tris- $\mathrm{HCl}$ buffer. To avoid the fluctuation due to the atmospheric carbon dioxide solubilisation, the reaction was carried out at a lower concentration of Tris- $\mathrm{HCl}$ buffer. For this assay $2 \times 2 \mathrm{~cm}^{2}$ dimensions of PET films were used to achieve effective stirring. At the initial period, PET hydrolysis was expressed as units of micromoles of sodium hydroxide $(\mathrm{NaOH})$ added to the milliliter of reaction volume per hour. Examination of cutinase activity for PET hydrolysis was performed at different temperature ranges from $30{ }^{\circ} \mathrm{C}-95{ }^{\circ} \mathrm{C}$ and $\mathrm{pH}$ of $5.5-9.0$. The cutinase enzyme and PET concentration for this assay ranges from $0-20 \mathrm{nmol} / \mathrm{mL}$ and $0-30 \mathrm{~cm}^{2} / \mathrm{mL}$, respectively. Reaction mixtures without cutinase enzyme were used as a control sample to illustrate the chemical degradation of PET. The cutinase enzyme-catalyzed PET hydrolysis was determined by subtracting the chemical hydrolysis from the total hydrolysis of PET.

\section{Results and Discussion}

\subsection{Isolation and screening of lipase and cutinase-producing organism.}

The isolated fungal species from the college premises (Rajalakshmi Engineering College, Chennai, Tamil Nadu, India) were screened for lipase production using the rhodamine agar plate method. The fluorescent halo zone formation around the well in the YPSS agar plate containing Rhodamine B (fluorescent dye) and olive oil indicates the production of lipase enzyme by the isolated fungal species was shown in Figure 1. The fluorescent halo zone was formed due to the interaction between the lipase enzyme and the olive oil substrate. From Figure 1, it was observed that the zone of about $1 \mathrm{~cm}$ indicates that the enzyme lipase has interacted with the olive oil substrate. In addition to this, the observed results were indicated the production of lipase by Aspergillus tamarii. 


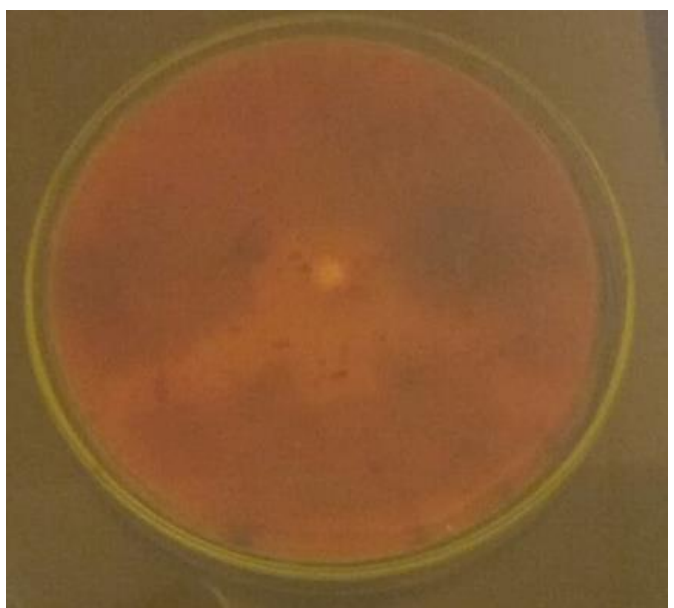

Figure 1. Fluorescent halo zone indicates the synthesis of lipase.

Like the screening of lipase-producing fungal species, cutinase-producing fungal species were also screened using the rhodamine agar plate method. The fluorescent halo zone around the well in the YPSS agar plate containing Rhodamine B colorant dye and cutin as substrate indicates the release of cutinase by the isolated fungal species. The zone produced was due to the interaction between the cutinase enzyme and the freshly prepared cutin substrate. Figure 2 shows Fluorescent halo zone indicates the synthesis of cutinase.

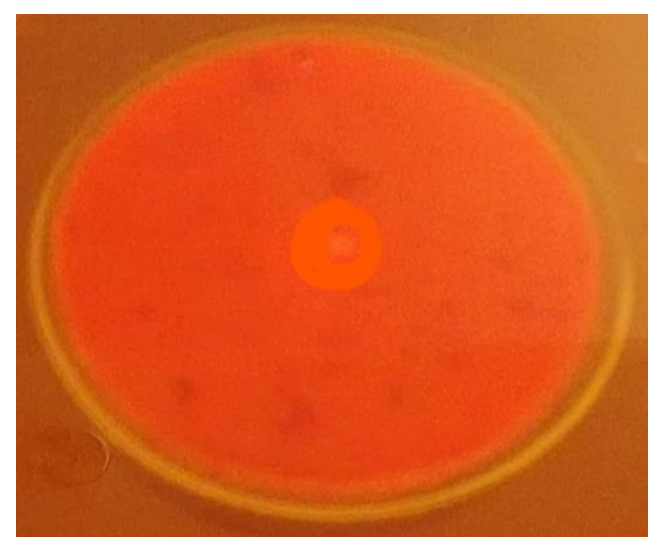

Figure 2. Fluorescent halo zone indicates the synthesis of cutinase.

In the last decade, esterase enzymes were used to hydrolyze plastics. The most common esterases, which cleaves the PET polymers, are cutinase, lipase, hydrogen peroxidases, and serine hydrolase. These enzymes were mostly isolated from bacterial and fungal species. Thus, in our studies, active lipase and cutinase from the commonly available fungus Aspergillus tamarii and cutinase from the Penicillium crustosum were chosen to study their ability to degrade the PET polymers (plastic). Other authors made several attempts to select several enzymes based on their natural role to hydrolyze ester bonds.

\subsection{Identification of lipase and cutinase producing fungal species.}

The isolated and screened lipase and cutinase-producing fungal species were identified as Aspergillus tamarii and Penicillium crustosum by $18 \mathrm{~S}$ rRNA sequencing method. The sequence of identified Aspergillus tamarii and Penicillium crustosum was shown in Figure 3(a) and 3(b), respectively. 


\begin{abstract}
TTCCGTAGGT GAACCT GCGGAAGGAT CATTACCGAGTGT AGGGTTCC TAGCGAGCCCAACCTCCCACCCGT GTTTACT GTAACCT TAGTT GCTTC GGCGGGCCCGCCTTTAAGGCCGCCGGGGGGCATCAGCCCCCGGGCC CGCGCCCGCCGGAGACACCACGAACTCTGTCTGATCTAGT GAAGTCT GAGTTGATT GTATCGCAATCAGTTAAAACTTTCAACAATGGATCTCTT GGT TCCGGCATCGATGAAGAACGCAGCGAAATGCGATAACT AGTGT AATTGCAGAATTCCGT GAATCATCGAGTCTTTGAACGCACATT GCGCC CCCTGGTATTCCGGGGGGCATGCCTGT CCGAGCGT CATT GCTGCCCA TCAAGCAC GGCTTGT GT GTT GGGT CGTCGTCCCCTCTT CGGGGGGGA CGGGCCCCAAAGGCAGCGGCGGCACCGCGTCCGATCCTCGAGCGTAT GGGGCTTTGT CACCCGCTCTGTAGGCCCGGCCGGCGCTTGCCGAACG CAAAACAACCATTCTTTCCAGGTTGACCTCGGATCAGGTAGGGATAC CCGCTGAACT TAAGCATATCAATAAGCGGAGGAA
\end{abstract}

Figure 3(a). Sequence of Aspergillus tamarii (Lipase producing fungal species).

\begin{abstract}
CGA GTGAGGGCCTCTGGGTCCAACCTCCCACCCGT GTTTATTTT ACCT TGTTGCTTCGGCGGGCCCGCCTTAACTGGCCGCCGGGGGGCTTACGC CCCCGGGCCCGCGCCCGCCGAAGACACCCTCGAACT CTGTCTGAAGA TTGAAGTCT GAGTGAAAATATAAATTATTTAAAACTTTCAACAACGGA TCTCTT GGT TCCGGCATCGATGAAGAACGCAGCGAAATGCGATACGT AATGTGAAT TGCAAATTCAGTGAATCATCGAGTCTT TGAACGCACATT GCGCCCCCTGT ATTCCGGGGGGCAT GCCTGTCCGAGCGTCATTGCTG CCCTCAAGCCCGGCTT GTGTGTTGGGCCCCGTCCCCCGATCTCCGGG GGACGGGCCCGAAAGGCAGCGGCGGCACCGCGT CCGGTCCTCGAGC GTATGGGGCTTTGTCACCCGCTCT GTAGGCCCGGCCGGCGCTTGCCG ATCAACCCAAATTTTTATCCAGGTTGACCTCGGATCAGGTAGGGATAC CCGCTGAACTTAAGCATATCAATAAGCGGAGGA
\end{abstract}

Figure 3(b). Sequence of Penicillium crustosum (Cutinase producing fungal species).

By using PhyML 3.0 aLRT program, the evolutionary relationship of Aspergillus tamarii and Penicillium crustosum with closely related other microbial sequences. The result from PhyML 3.0 aLRT was obtained as a phylogenetic tree was shown in Figures 4(a) and 4(b), respectively, for Aspergillus tamarii and Penicillium crustosum.

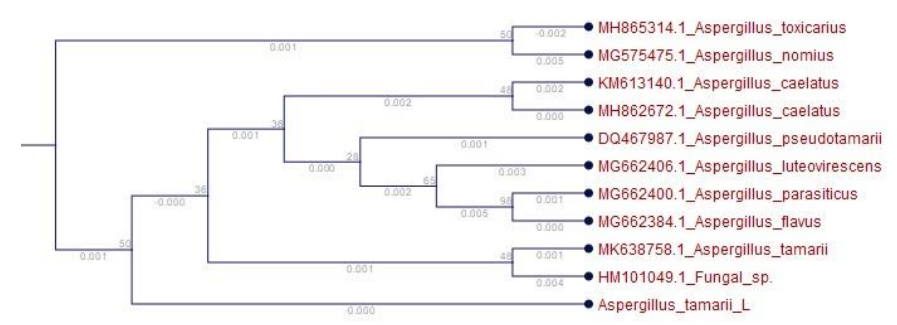

Figure 4(a). Phylogenetic tree - Aspergillus tamarii (Lipase producing fungal species)

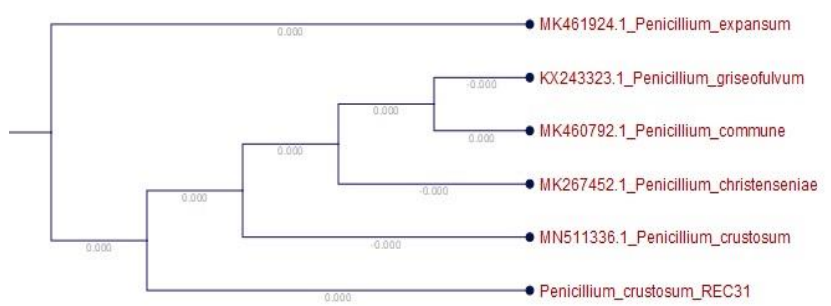

Figure 4(b). Phylogenetic tree - Penicillium crustosum (Cutinase producing fungal species).

\title{
3.3. Titrimetric assay for lipase activity.
}

The activity of lipase is identified through titrimetric assay using the formula. The volume of $\mathrm{NaOH}$ required to react with the reactant mixture is $1.8 \mathrm{~mL}$. The dilution factor is obtained as 1.02 . Thus, lipase activity produced by the Aspergillus tamarii was found to be 4.916 units/mL. 


\subsection{Estimation of total protein content by Lowry`s method.}

The total amount of protein produced by each organism under study was estimated by Lowry's method is:

the amount of protein produced by Aspergillus tamarii $=23 \mathrm{mg} / \mathrm{mL}$.

the amount of protein produced by Penicillium crustosum $=5.75 \mathrm{mg} / \mathrm{mL}$.

table 1 and 2 show the estimation of total protein content for Aspergillus tamarii and Penicillium crustosum, respectively. The graph was plotted against BSA concentration and absorbance at $650 \mathrm{~nm}$ to obtain the protein content and shown in Figures 5(a) and 5(b) for Aspergillus tamarii and Penicillium crustosum, respectively.

Table 1. Estimation of total protein content for Aspergillus tamarii by Lowry test.

\begin{tabular}{l|l|l|l|l|l|l} 
Concentration of BSA & 0.05 & 0.10 & 0.15 & 0.20 & 0.25 & Test \\
\hline Absorbance $-\mathbf{6 5 0} \mathbf{~ n m}$ & 0.061 & 0.075 & 0.086 & 0.191 & 0.234 & 0.195
\end{tabular}

Table 2. Estimation of total protein content for Penicillium crustosum by Lowry test.

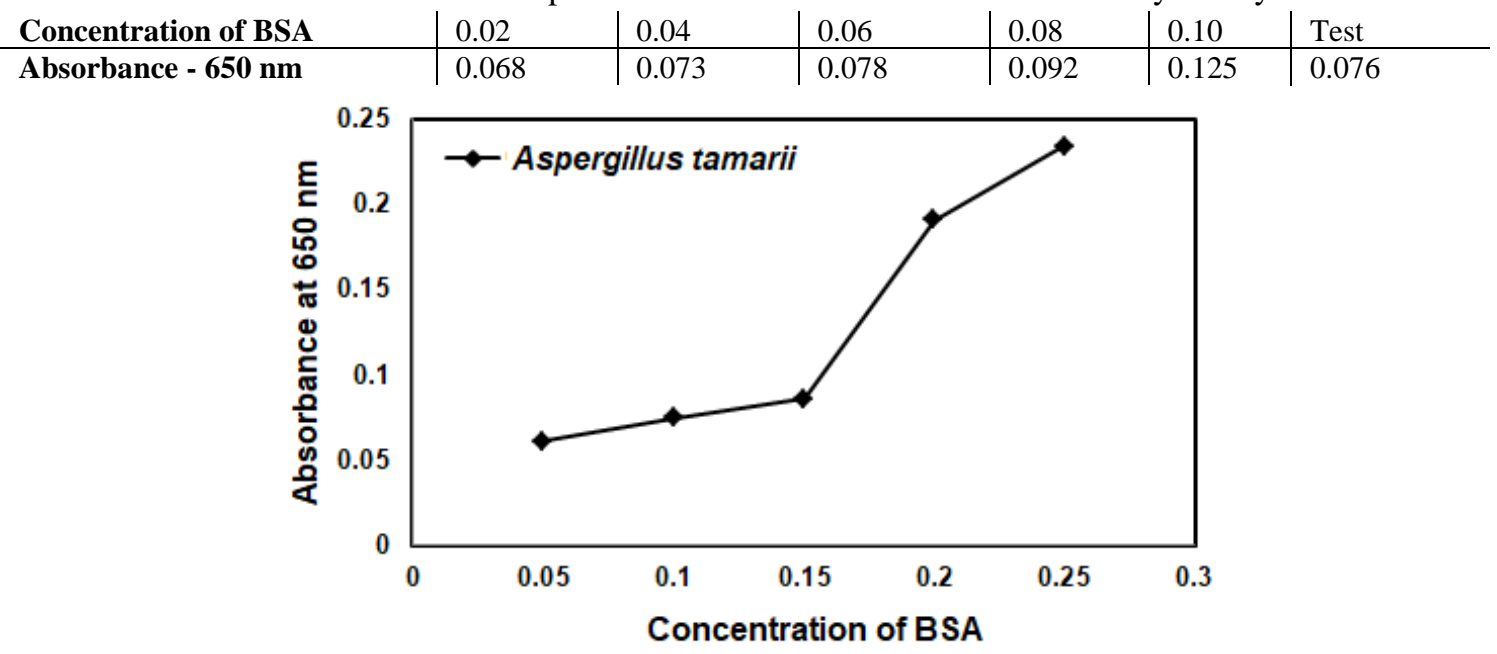

Figure 5(a). Protein estimation by Lowry's method for Aspergillus tamarii.

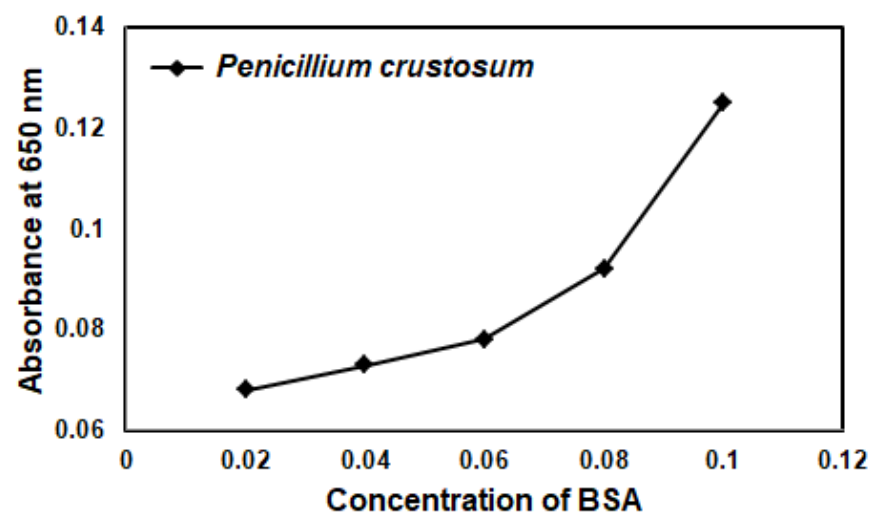

Figure 5(b). Protein estimation by Lowry's method for Penicillium crustosum.

\subsection{Analysis of degraded products.}

The separation of TPA, and PEG was achieved by HPLC using a reversed-phase column run under isocratic conditions with UV detection. The HPLC result for the release of TPA and PEG was shown in Figure 6(a), and Figure 6(b) shows the HPLC result for the standard PEG to compare with the degraded product results. In Figure 6(a), the retention time indicates the release of TPA and PEG. This allowed the construction of calibration curves for these compounds from 0.5 to $25 \mu \mathrm{g} / \mathrm{mL}$ with $\mathrm{R}^{2}$ values of 0.997 . 


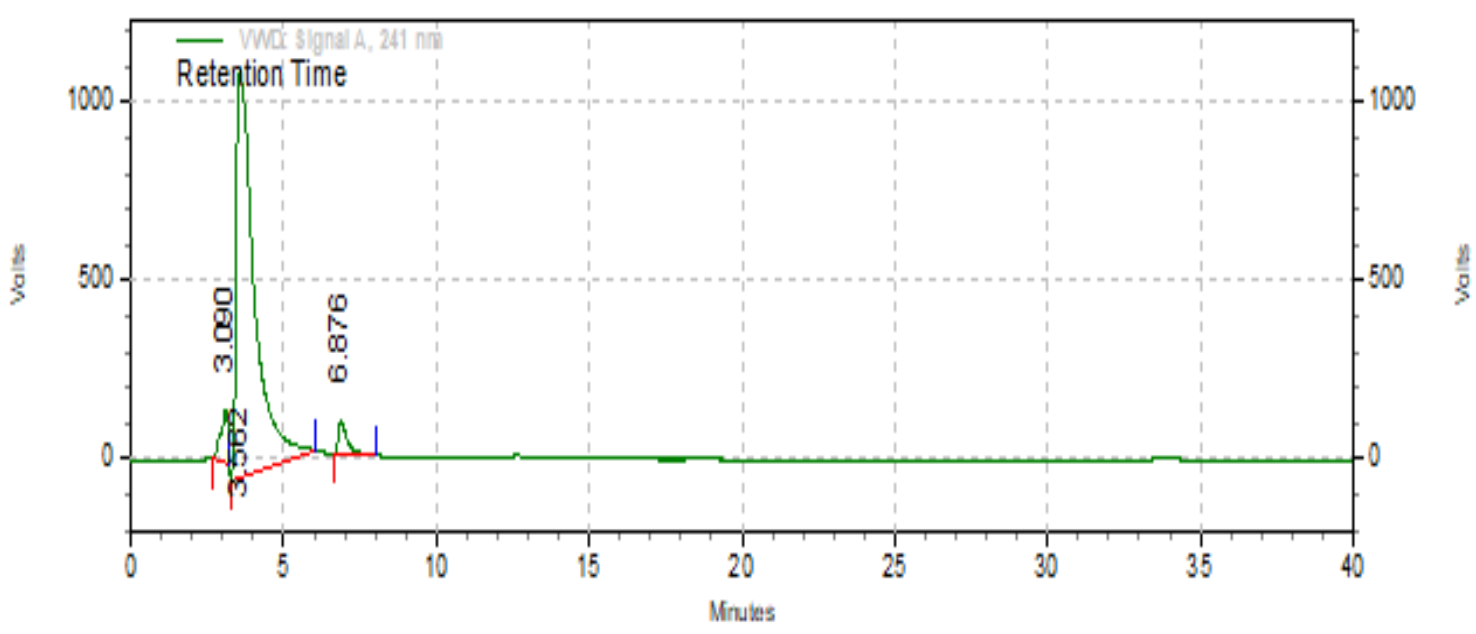

Figure 6(a). HPLC result for the release of TPA and PEG.

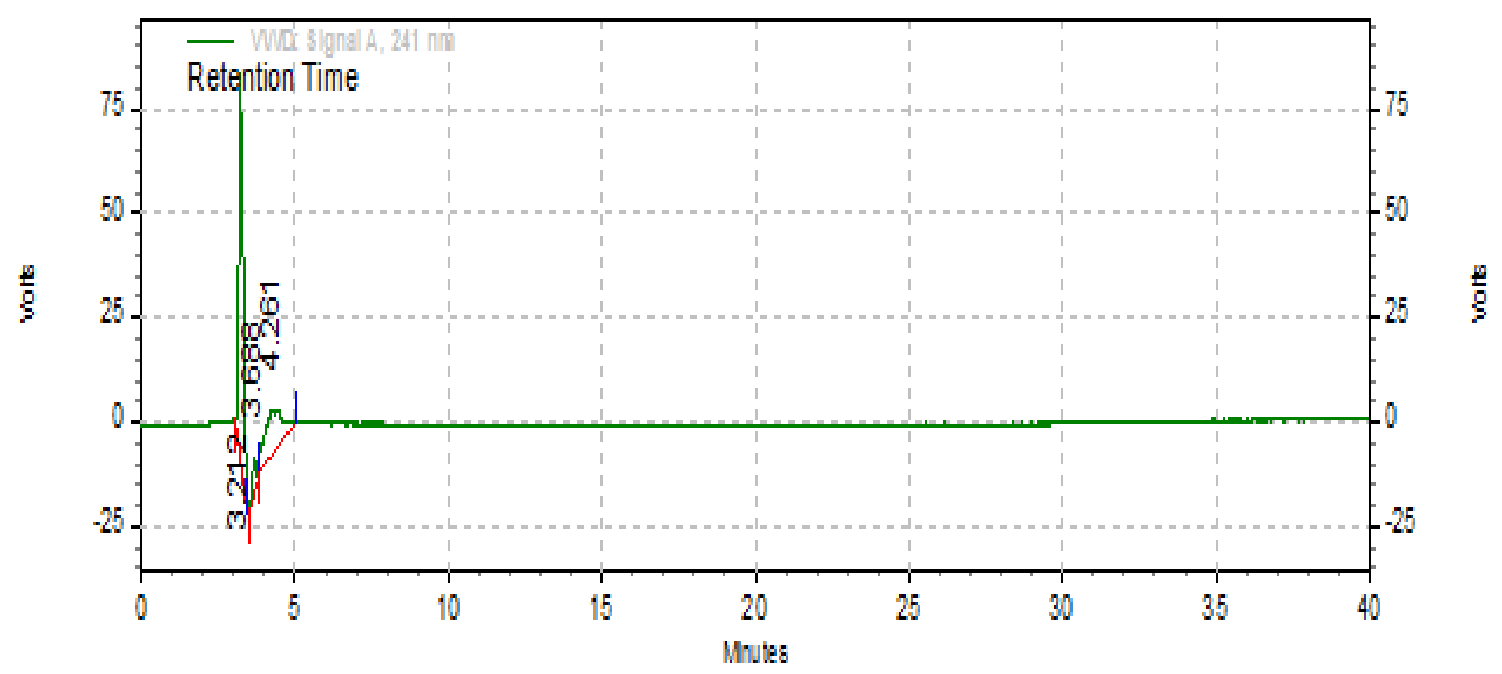

Figure 6(b). HPLC result for the standard PEG to compare with the degraded product results.

After 30 days incubation of 5 PET films with Aspergillus tamarii and the isolated enzymes in $75 \mathrm{~mL}$ of YPSS media showed TPA and PEG release. This release was identified using HPLC. From Figure 6(a), the peak at the $6^{\text {th }}$ minute indicates the release of TPA. The release was calculated to be approx. $3.53 \%$ i.e., $3.5 \mathrm{mg} / \mathrm{mL}$. From Figure 6(b), the peak at the $3^{\text {rd }}$ minute indicates the release of PEG. The release was about $4.51 \%$, i.e., $4.5 \mathrm{mg} / \mathrm{mL}$. These retention values are very specific to the mobile phase consisting of $70 \%$ distilled water, $20 \%$ acetonitrile, and $10 \%$ formic acid solution (v/v), at a flow rate of $1 \mathrm{~mL} / \mathrm{min}$ a wavelength of about $241 \mathrm{~nm}$.

\subsection{Characterization studies.}

\subsubsection{FTIR analysis.}

The strong white item gotten through PET soluble hydrolysis after unreacted PET was isolated was portrayed by the chronicle of FT-IR spectra to be affirmed as Terephthalic acid. Figure 7(a) shows that FTIR images of cutinase catalyzed PET hydrolysis, and Figure 7(b) shows that FTIR images of PET hydrolysis by lipase enzyme. Most polymers contain crystalline and formless areas; the contrasts between the group's force from IR range can be assigned to diverse dispersions of these districts. 


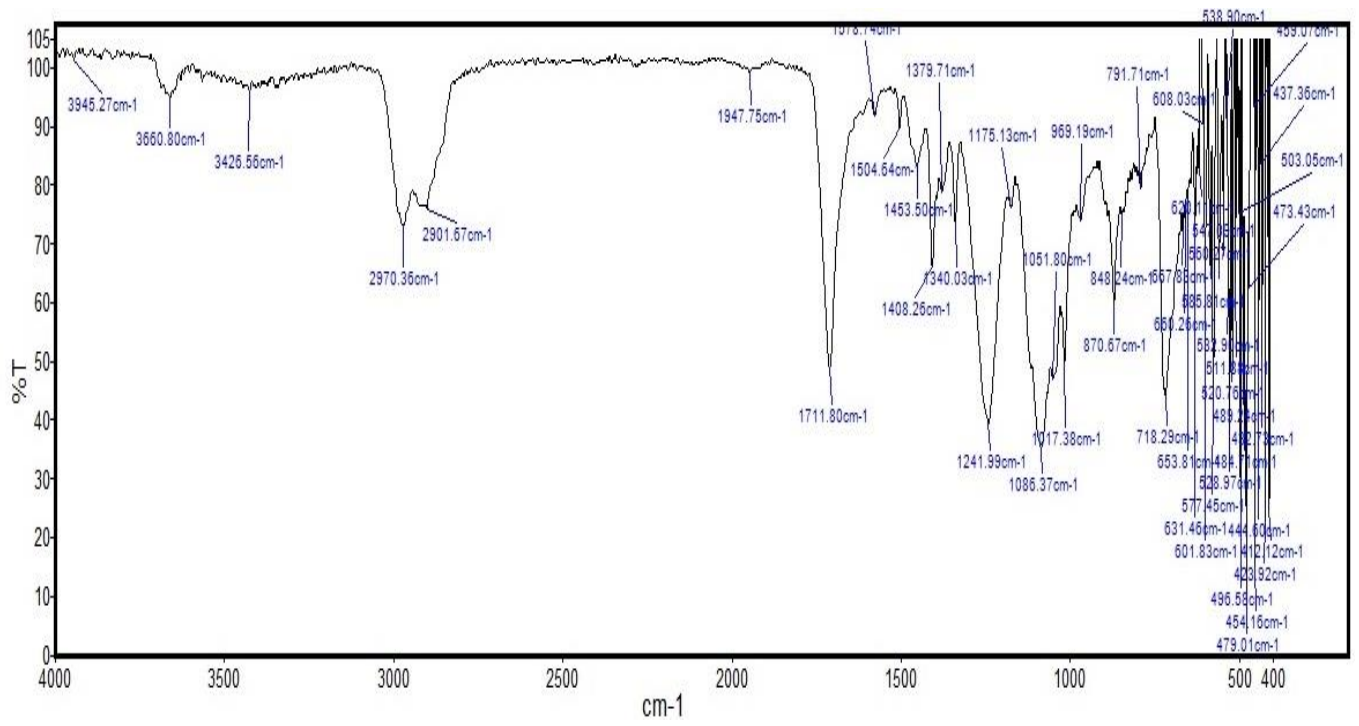

Figure 7(a). FTIR images of cutinase catalyzed PET hydrolysis.

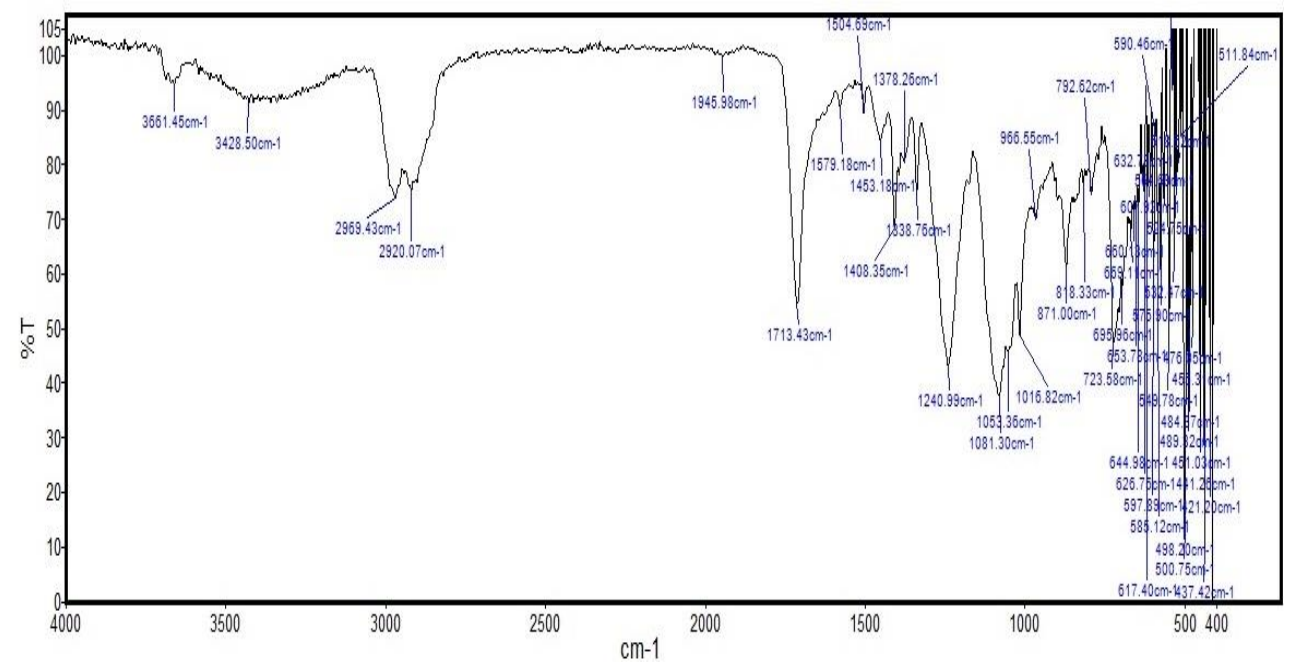

Figure 7(b). FTIR images of PET hydrolysis by lipase enzyme.

In Figure 7(a), bands at 3660 and $3426 \mathrm{~cm}^{-1}$ correspond to the alcohol group frequencies of OH hydroxyl group. The peak values at 2970 and $2901 \mathrm{~cm}^{-1}$ show the presence of aliphatic group frequencies of methyl $\mathrm{C}-\mathrm{H}$ asymmetric stretch. The intense broadband at $1711 \mathrm{~cm}^{-1}$ represents the carbonyl group frequency of carboxylic acid. In Figure 7(b), the peak value at $2920 \mathrm{~cm}^{-1}$ represents the aliphatic group frequency of methylene $\mathrm{C}-\mathrm{H}$ asymmetric stretch. The broadband at $1945 \mathrm{~cm}^{-1}$ represents the presence of isothiocyanate-bands at 1579 and 1504 $\mathrm{cm}^{-1}$ attributed to hetero-oxy compounds of aliphatic and aromatic nitro compounds.

\subsubsection{SEM analysis.}

The morphologic portrayal is an essential standard that can decide the material application. It's anything but a typical portrayal method utilized for PET monomers. The effect on surface roughness of PET layer due to the action of fungal species was studied using SEM images. Figure 8 shows the SEM image of unreacted PET. The image shows the surface roughness and the hole that penetrate beneath the surface, indicating species' growth by utilizing the PET as substrate. The SEM results can be utilized to interpret the total depolymerization since the PET morphology is crystalline and its monomers present a 
shapeless morphology. Furthermore, they are formed via carbon and oxygen since the monomers are natural mixes.

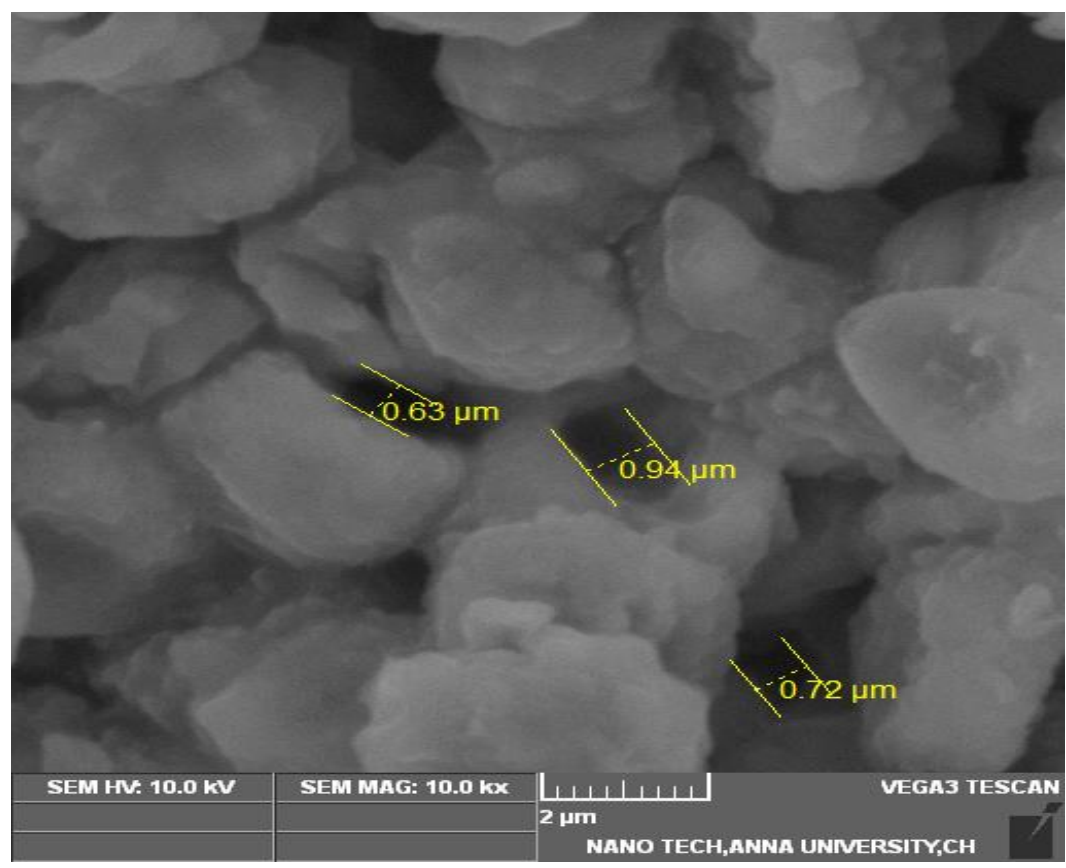

Figure 8. SEM analysis of unreacted PET.

\subsection{Cutinase catalyzed PET hydrolysis.}

Cutinase activity for PET hydrolysis was examined by calculating the amount of $\mathrm{NaOH}$ consumed at different time intervals using $\mathrm{pH}$-stat. Reaction mixture $\mathrm{pH}$ in the $\mathrm{pH}$-stat was maintained as constant by $\mathrm{NaOH}$ titration during cutinase catalyzed PET hydrolysis. Experiments were conducted at different temperatures $\left(30{ }^{\circ} \mathrm{C}-95^{\circ} \mathrm{C}\right)$ and $\mathrm{pH}(5.5-9.0)$ to evaluate their effects on cutinase catalyzed PET hydrolysis. Results were shown in Figures 9 and 10 for the effect of temperature and $\mathrm{pH}$ on PET hydrolysis, respectively. From Figure 9, it was observed that an increase in temperature increases the PET hydrolysis until the temperature $80{ }^{\circ} \mathrm{C}$ reaches the cutinase activity as $10.62 \mu \mathrm{mol} / \mathrm{mL} / \mathrm{h}$ after that, it decreased due to the thermal-induced denaturation of the cutinase enzyme. Figure 10 shows the effect of $\mathrm{pH}$ on cutinase catalyzed PET hydrolysis, in that the hydrolysis was increased while increasing the $\mathrm{pH}$ from 5.5 to 9.0 at constant temperature $\left(80^{\circ} \mathrm{C}\right)$. In that, the PET hydrolysis reaches a maximum $(13.68 \mu \mathrm{mol} / \mathrm{mL} / \mathrm{h})$ at the $\mathrm{pH}$ of 8.5 ; after that, cutinase enzyme activity was decreased and reached $3.04 \mu \mathrm{mol} / \mathrm{mL} / \mathrm{h}$ at the $\mathrm{pH}$ of 9.0 .

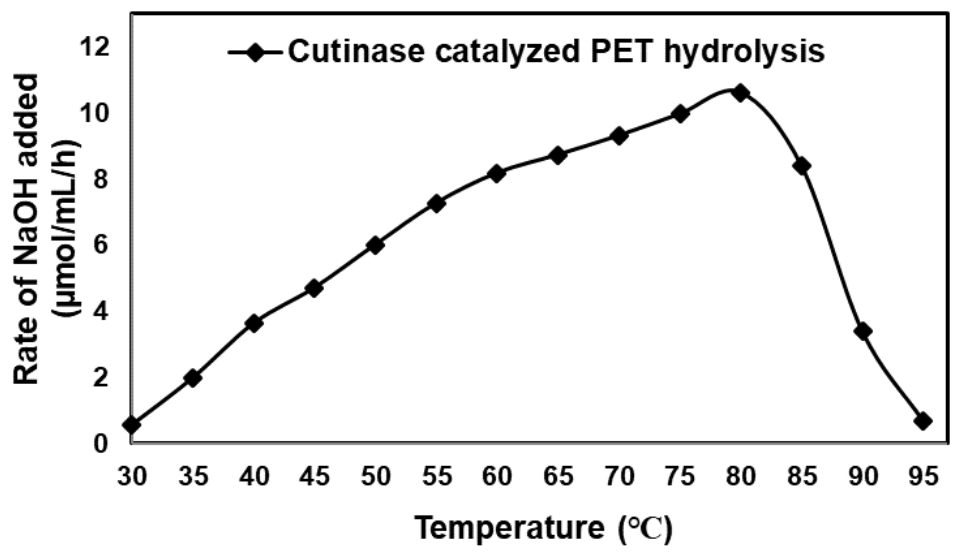

Figure 9. Effect of Temperature on cutinase catalyzed PET hydrolysis. 


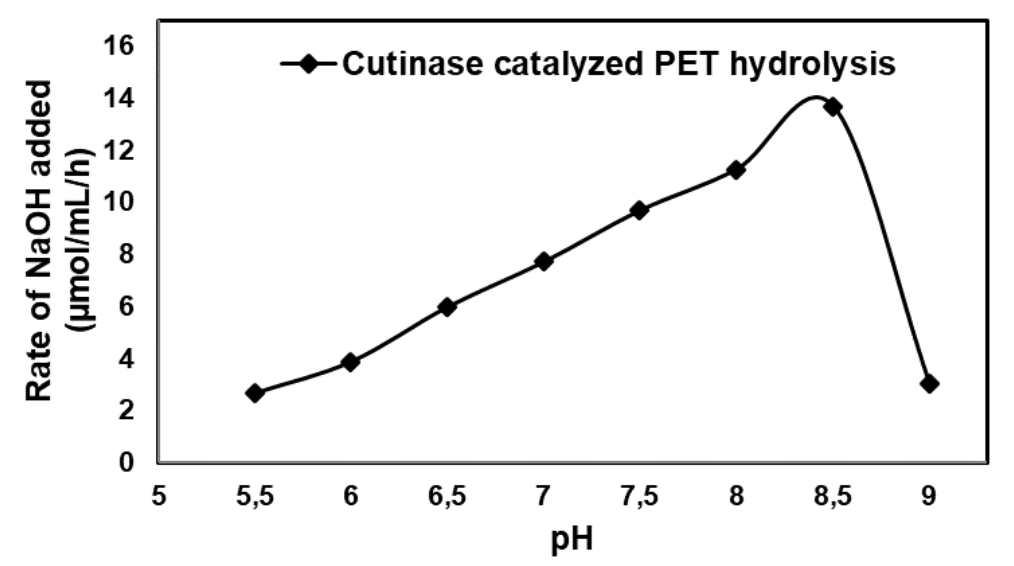

Figure 10. Effect of pH on cutinase catalyzed PET hydrolysis.

\section{Conclusions}

The present study focused on evaluating the capability of enzymes lipase and cutinase was extracted from the fungal species isolated from soil to hydrolyze mineral water bottles (PET). The isolated fungal species were identified as Aspergillus tamarii and Penicillium crustosum by $18 \mathrm{~S}$ rRNA sequencing method. Further optimization of reaction conditions such as temperature, $\mathrm{pH}$, the concentration of enzymes, and PET films' concentration has been studied. The amounts of protein content in both the isolated fungal species were evaluated by Lowry's method. Further optimization of substrate concentration can be done when SEM and FTIR analysis were carried out. The result concludes that effective biodegradation of PET in a short period by cutinase and lipase enzymes. By this method, the non-pathogenic bioproduct (enzymes) of Aspergillus tamarii and Penicillium crustosum effectively degrades the PET. Thus, we can effectively degrade the PET without limiting the use of plastics. This investigation gives an eco-friendly clarification by microbial consortia for the disposal of plastic from the condition. Present examination explores an eco-friendly, proficient, and financially savvy approach for plastic waste administration by screening novel microbial consortia, which are fit for debasing plastic polymers.

\section{Funding}

This research received no external funding.

\section{Acknowledgments}

This research has no acknowledgment.

\section{Conflicts of Interest}

The authors declare no conflict of interest.

\section{References}

1. Yoshida, S.; Hiraga, K.; Takehana, T.; Taniguchi, I.; Yamaji, H.; Maeda, Y.; Toyohara, K.; Miyamoto, K.; Kimura, Y.; Oda, K. A bacterium that degrades and assimilates poly (ethylene terephthalate). Sci. 2016, 351, 1196-1199, https://doi.org/10.1126/science.aad6359.

2. Das, P.; Tiwari, P. Thermal degradation study of waste polyethylene terephthalate (PET) under inert and oxidative environments. Thermochim. Acta. 2019, 679, https://doi.org/10.1016/j.tca.2019.178340. 
3. Law, K.L. Plastics in the Marine Environment. Ann. Rev. Mar. Sci. 2017, 9, 205-229, https://doi.org/10.1146/annurev-marine-010816-060409.

4. Taghavi, N.; Singhal, N.; Zhuang, W-Q.; Baroutian, S. Degradation of plastic waste using stimulated and naturally occurring microbial strains. Chemosphere. 263, https://doi.org/10.1016/j.chemosphere.2020.127975.

5. Zander, N.E.; Gillan, M.; Lambeth, R.H. Recycled polyethylene terephthalate as a new FFF feedstock material. Addit. Manuf. 2018, 21, 174-182, https://doi.org/10.1016/j.addma.2018.03.007.

6. Hou, L.; Kumar, D.; Yoo, C.G.; Gitsov, I.; Majumder, E.L.-W. Conversion and removal strategies for microplastics in wastewater treatment plants and landfills. Chem. Eng. J. 2021, 406, https://doi.org/10.1016/j.cej.2020.126715.

7. Chen, C.; Chen, L.; Li, Y.; Fu, W.; Shi, X.; Duan, J.; Zhang, W. Impacts of microplastics on organotins' photodegradation in aquatic environments. Environ. Pollut. 2020, 267, https://doi.org/10.1016/j.envpol.2020.115686.

8. Kumar, S.; Teotia, U.V.S.; Singh, Y. A comprehensive review on microbial degradation of plastic waste. J. Appl. Pharm. Res. 2017, 5, 8-12.

9. Jain, P.; Jain, A.; Singhai, R.; Jain, S. Effect of Biodegradation and Non Degradable Substances in Environment. Int. J. Life Sci. 2017, 1, 58-64.

10. Stojkovic, M.; Stojkovic, P.; Stankovic, K.M. Human pluripotent stem cells - Unique tools to decipher the effects of environmental and intracellular plastic pollution on human health. Environ. Pollut. 2021, 269, https://doi.org/10.1016/j.envpol.2020.116144.

11. Koelmans, A.A.; Besseling, E.; Foekema, E.; Kooi, M.; Mintenig, S.; Ossendorp, B.C.; RedondoHasselerharm, P.E.; Verschoor, A.; van Wezel, A.P.; Scheffer, M. Risks of Plastic Debris: Unravelling Fact, Opinion, Perception and Belief. Environ. Sci. Technol. 2017, 51, 11513-11519, https://doi.org/10.1021/acs.est.7b02219.

12. Weinstein, J.E.; Dekle, J.L.; Leads, R.R.; Hunter, R.A. Degradation of bio-based and biodegradable plastics in a salt marsh habitat: Another potential source of microplastics in coastal waters. Mar. Pollut. Bull. 2020, 160, https://doi.org/10.1016/j.marpolbul.2020.111518.

13. Sheng, C.; Zhang, S.; Zhang, Y. The influence of different polymer types of microplastics on adsorption, accumulation, and toxicity of triclosan in zebrafish. J. Hazard. Mater. 2021, 402, https://doi.org/10.1016/j.jhazmat.2020.123733.

14. Skariyachan, S.; Megha, M.; Kini, M.N.; Mukund, K.M.; Rizvi, A.; Vasist, K. Selection and screening of microbial consortia for efficient and ecofriendly degradation of plastic garbage collected from urban and rural areas of Bangalore, India. Environ. Monit. Assess. 2015, 187, https://doi.org/10.1007/s10661-0144174-y.

15. Tanasupawat, S.; Takehana, T.; Yoshida, S.; Hiraga, K.; Oda, K. Ideonella sakaiensis sp. nov., isolated from a microbial consortium that degrades poly (ethylene terephthalate). Int. J. Syst. Evol. Microbiol. 2016, 66, 2813-2818, https://doi.org/10.1099/ijsem.0.001058.

16. Sanchez, C. Fungal potential for the degradation of petroleum-based polymers: An overview of macro- and microplastics biodegradation. Biotechnol. Adv. 2020, 40, https://doi.org/10.1016/j.biotechadv.2019.107501.

17. Muenmee, S.; Chiemchaisri, W.; Chiemchaisri, C. Enhancement of biodegradation of plastic wastes via methane oxidation in semi-aerobic landfill. Int. Biodeterior. Biodegrad. 2016, 113, 244-255, https://doi.org/10.1016/j.ibiod.2016.03.016.

18. Karamanlioglu, M.; Preziosi, R.; Robson, G. Abiotic and biotic environmental degradation of the bioplastic polymer poly (lactic acid): A review. Polym. Degrad. Stab. 2017, 137, 122-130, https://doi.org/10.1016/j.polymdegradstab.2017.01.009.

19. Singh, B.; Sharma, N. Mechanistic implications of plastic degradation. Polym. Degrad. Stab. 2008, 93, 561584, https://doi.org/10.1016/j.polymdegradstab.2007.11.008.

20. Sil, D.; Chakrabarti, S. Photocatalytic degradation of PVC-ZnO composite film under tropical sunlight and artificial UV radiation: A comparative study. Sol. Energy. 2010, 84, 476-485, https://doi.org/10.1016/j.solener.2009.09.012.

21. Miyakawa, T.; Mizushima, H.; Ohtsuka, J.; Oda, M.; Kawai, F.; Tanokura, M. Structural basis for the $\mathrm{Ca}(2+)$-enhanced thermostability and activity of PET-degrading cutinase-like enzyme from Saccharomonospora viridis AHK190. Appl. Microbiol. Biotechnol. 2015, 99, 4297-4307, https://doi.org/10.1007/s00253-014-6272-8.

22. Da Costa, A.M.; Lopes, V. R.O.; Vidal, L.; Nicaud, J.M.; de Castro, A.M.; Coelho, M.A.Z. Poly(ethylene terephthalate) (PET) degradation by Yarrowia lipolytica: investigations on cell growth, enzyme production and monomers consumption. Process Biochem. 2020, 95, 81-90, https://doi.org/10.1016/j.procbio.2020.04.001.

23. Urbanek, A.K.; Mirończuk, A.M.; García-Martín, A.; Saborido, A.; de la Mata, I.; Arroyo, M. Biochemical properties and biotechnological applications of microbial enzymes involved in the degradation of polyestertype plastics. Biochim. Biophys. Acta (BBA) - Proteins Proteomics 2020, 1868, https://doi.org/10.1016/j.bbapap.2019.140315. 
24. Shi, K.; Jing, J.; Song, L.; Su, T.; Wang, Z.Enzymatic hydrolysis of polyester: Degradation of poly( $\varepsilon^{-}$ caprolactone) by Candida antarctica lipase and Fusarium solani cutinase. Int. J. Biol. Macromol. 2020, 144, 183-189, https://doi.org/10.1016/j.ijbiomac.2019.12.105.

25. Su, L.; Hong, R.; Kong, D.; Wu, J. Enhanced activity towards polyacrylates and poly(vinyl acetate) by sitedirected mutagenesis of Humicola insolens cutinase. Int. J. Biol. Macromol. 2020, 162, 1752-1759, https://doi.org/10.1016/j.ijbiomac.2020.07.261.

26. Degani, O. Production and Purification of Cutinase from Fusarium oxysporum Using Modified Growth Media and a Specific Cutinase Substrate. Adv. Biosci. Biotechnol. 2015, 6, 245-258, https://doi.org/10.4236/abb.2015.64024.

27. Gamerith, C.; Vastano, M.; Ghorbanpour, S.M.; Zitzenbacher, S.; Ribitsch, D.; Zumstein, M.T.; Sander, M.; Acero, E.H.; Pellis, A.; Guebitz, G.M. Enzymatic Degradation of Aromatic and Aliphatic Polyesters by $P$. pastoris Expressed Cutinase 1 from Thermobifida cellulosilytica. Front. Microbiol. 2017, 24, https://doi.org/10.3389/fmicb.2017.00938.

28. Wu, F.; Ma, J.; Cha, Y.; Lu, D.; Li, Z.; Zhuo, M.; Luo, X.; Li, S.; Zhu, M. Using inexpensive substrate to achieve high-level lipase A secretion by Bacillus subtilis through signal peptide and promoter screening. Process Biochem. 2020, 99, 202-210, https://doi.org/10.1016/j.procbio.2020.08.010.

29. Phukon, L.C.; Chourasia, R.; Kumari, M.; Godan, T.K.; Sahoo, D.; Parameswaran, B.; Rai, A.K. Production and characterisation of lipase for application in detergent industry from a novel Pseudomonas helmanticensis HS6. Bioresour. Technol. 2020, 309, https://doi.org/10.1016/j.biortech.2020.123352.

30. Che, J.; Sun, B.; Zhang, P.; Xu, W.; Liu, Y.; Xiong, B.; Tang, K. Immobilization of lipase AYS on UiO-66NH2 metal-organic framework nanoparticles as a recyclable biocatalyst for ester hydrolysis and kinetic resolution. Sep. Purif. Technol. 2020, 251, https://doi.org/10.1016/j.seppur.2020.117398.

31. Suseela, L.; Anupama, M.; Prudhvilal, B.; Narasaiah, T.V.; Latha, J.N.L. Isolation \& characterization of lipase producing fungi from palm oil mill effluent obtained from Pedavegi, A.P., India. Int. J. Biol. Pharm. Res. 2014, 5, 559-565.

32. Heumann, S.; Eberl, A.; Pobeheim, H.; Liebminger, S.; Fisher-Colbrie, G.; Almansa, E.; Cavaco-Paulo, A.; Gubitz, G.M. New model substrates for enzymes hydrolysing polyethyleneterephthalate and polyamide fibres. J. Biochem. Biophys. Methods. 2006, 69, 89-99, https://doi.org/10.1016/j.jbbm.2006.02.005.

33. Carniel, A.; Valoni, E.; Junior, J.N.; Gomes, A.C.; de Castro, A.M. Lipase from Candida antarctica (CALB) and cutinase from Humicola insolens act synergistically for PET hydrolysis to terephthalic acid. Process Biochem. 2017, 59, 84-90, https://doi.org/10.1016/j.procbio.2016.07.023.

34. Maeda, H.; Yamagata, Y.; Abe, K.; Hasegawa, F.; Machida, M.; Ishioka, R.; Gomi, K.; Nakajima, T. Purification and characterization of a biodegradable plastic-degrading enzyme from Aspergillus oryzae. Appl. Microbiol. Biotechnol. 2005, 67, 778-788, https://doi.org/10.1007/s00253-004-1853-6.

35. Carta, D.; Cao, G.; D’Angeli, C. Chemical recycling of Poly (ethylene terephthalate) (PET) by hydrolysis and glycolysis. Environ. Sci. Pollut. Res. 2003, 10, 390-394, https://doi.org/10.1065/espr2001.12.104.8.

36. Kumagai, S.; Hirahashi, S.; Grause, G.; Kameda, T.; Toyoda, H.; Yoshioka, T. Alkaline hydrolysis of PVCcoated PET fibers for simultaneous recycling of PET and PVC. J. Mater. Cycle. Waste Manag. 2018, 20, 439-449, https://doi.org/10.1007/s10163-017-0614-4. 